\title{
LETTERS
}

\section{The well-off can also be vulnerable toward the end of life}

I find it astonishing that respected researchers could think large data numbercrunching could lead to valid conclusions on patient safety in the age of medical assistance in dying (MAiD).

On the basis of only the number of palliative care contacts among patients who die from MAiD, Downar and colleagues conclude both that palliative care was unable to relieve patients' suffering, and that a lack of palliative care access was not driving requests. ${ }^{1}$ The variability in quality and training among services that call themselves "palliative care" is well known. Moreover, the study does not distinguish between a single visit and fullservice palliative care.

The authors also conclude that, as "traditionally vulnerable demographic groups" were underrepresented in the group dying from MAiD, it is "unlikely to be driven by social or economic vulnerability."

Dr. Balfour Mount tells the story of a patient, a prominent businessman who was given a diagnosis of advanced cancer. ${ }^{2}$ At the time of admission to the palliative care unit of Montréal's Royal Victoria Hospital, the patient was silent while his wife explained that he had had enough and pleaded for things to be over quickly. When Dr. Mount later returned to speak with the patient alone, he broke down in tears and confided, "I'm so afraid of being a burden."2

In my work in geriatrics I have seen vulnerability in rundown, bug-infested apartments with no food and no clean sheets. But I have also seen it in palatial houses, where virtually the only visits are from people paid to provide care, while others hover on the periphery, waiting for the inheritance. Riches are far from being a protection against coercion to die.
The connection between the data and the conclusions in this study is tenuous at best. To what end? What urgency is there to label the MAiD experiment as safe, prematurely and without evidence?

\section{Catherine Ferrier MD}

Physician, Division of Geriatric Medicine, McGill University Health Centre, Montréal, Que.

Cite as: CMAJ 2020 May 19;192:E557. doi: $10.1503 / \mathrm{cmaj} .74919$

\section{References}

1. Downar D, Fowler RA, Halko R, et al. Early experience with medical assistance in dying in Ontario, Canada: a cohort study. CMAJ 2020;192:E173-81.

2. Phillips D. The father of palliative care in Canada, physician Balfour Mount on the legacy of Cicely Saunders, the start of palliative care, and the true meaning of medical aid in dying. Montréal: McGill University; 2013. Available: www.mcgill. ca/palliativecare/portraits-0/balfour-mount (accessed 2020 Apr. 3).

Competing interests: None declared. 